\title{
Study on Distance Education to Adult Students in New Media Background based on Computer Technology
}

\author{
Ying Pan \\ Adults and Continuing Education, Beihua University, Jilin, China
}

\begin{abstract}
In the context of new media, traditional adult students' distance education has been an unprecedented challenge to the current distance education of adult students to fully understand the importance of the use of new media, necessity, and through new media the student population is widely popular media to develop and strengthen distance education of adult students, so as to continuously improve the effectiveness of distance education, and improve the quality of personnel training. In this paper, the characteristics of the new media, the impact of new media and how to use distance education of adult students as well as to strengthen the distance education of adult students three elaborate.
\end{abstract}

\section{General instruction}

With the continuous development of China's market economy, improve, life-long learning the knowledge economy has been widely recognized under social, adult higher education should once again usher in the spring of rapid development, but students of Adult Higher Continuing Education has reduced year by year, adult recognition of higher education community to continue declining. Analysis of the reasons is the following aspects: (1) college enrollment, self-examination of the shunt. (2) Continuing education and training of adult higher goals are not clear, unscientific; resulting in no significant effect of continuing education training, training of personnel can not meet the needs of socialist modernization. Deal with the problems, scholars have put forward correct school of thought, insist on serving the community and training of personnel to perform functions; flexible school system, and effectively meet the social needs of adults continue to learn; to achieve academic education and job training to improve the quality changes. From the academic point of view than the macro-level analysis of the Adult Higher Education and General Higher Education continues reasonable division of labor discussed the essential attribute of adult higher education and continuing training objectives, from the point of view of the basis of the quality of personnel training of adult higher education continues to present problems and solutions.

In cultivating innovative educational and cultural backgrounds innovative thinking talent, the Chinese Adult Education also shoulder the heavy responsibility of innovation and social development. Innovation is the soul of national progress, "Gou Nisshin, Japan Nisshin also Nisshin" culture of innovation is an important connotation of advanced culture, a culture of innovation and create an atmosphere conducive to innovative activity is generated in the production activities associated with the social value system as a whole and its results innovative forms combined. This article continues to follow the basic rules of adult higher education, in line with the content of education and innovation, education concept innovation, education and means of communication in the form of innovation and innovative ideas put forward in the context of the whole social innovation, the core content of adult higher education is continuing students innovative consciousness and ability to target, according to the development trend of adult higher education continues, in fact, made possible the development of ideas to help the development of our country for the development of adult higher education institutions to continue.

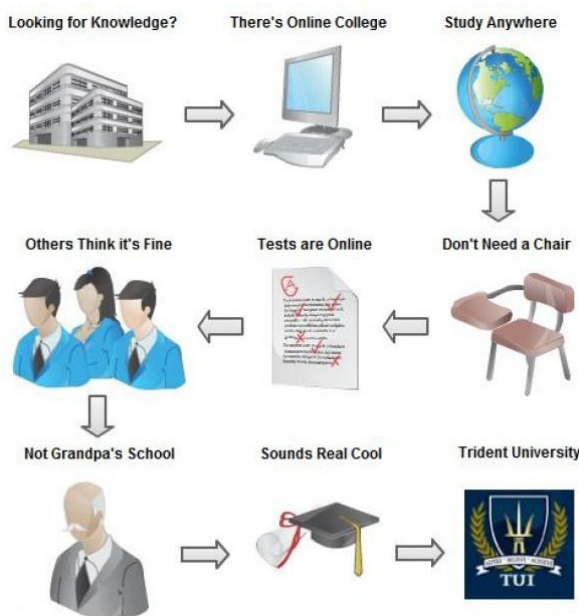

Figure 1. Online college 


\section{Adult higher educations continues to achieve the diversification}

Since the founding of adult higher education continues to achieve the diversification of higher education, improve the structure of the system of higher education. Access to higher education meets the aspirations of the people, while actively promoting the popularization of higher education process. Our Adult Higher Education for Adult Continuing Education, to enhance the level of knowledge provides an important way to meet the diversified market economy, the development process of the educational needs of different groups of people, train outstanding talent as a market economy of China's socialist construction and reform made great contribution. However, the development of adult higher education has continued, but there are still many problems.

Since the Department of Adult Education Adult Education formerly responsible for managing the development of functional differentiation Planning Division, Basic Education, Department of Higher Education, Division after college students, resulting in higher fuzzy adult continuing education status, resulting in the management process prone to blind spots, affecting healthy and orderly development of adult education. In addition, China to develop a complete no adult education laws, with the continuous progress of adult higher education popularization process for the new high-level job training in the form of adult higher education, age education, leisure and education does not correspond to adult education, lifelong education law guide, specification, build lifelong education, public vision of a learning society will not really implemented.

Adult higher education community on the utilitarian value orientation is mainly reflected in the pursuit of onesided and one-sided pursuit of academic skills in two ways. If the adult learners to pursue higher education for the purpose of Adult Continuing Education, the adult learners in the learning process will be to re-examination by getting educated, to improve their quality in the second. The adult higher education organizations continue to need income to meet the needs of the candidate's access to educational qualifications, in terms of personnel training and examination process reduces the standard. The adult higher education as a single continuing technical education, the educational process as a way to get to work, thus ignoring the humanities enhance adult learners, resulting in reduced quality of training Adult Higher Education. In addition, continuing adult higher education did not really get the same higher education and general social acceptance, is widely recognized that the presence of adult higher education entrance requirements, low quality of training, strict examination requirements and other issues. These cognitive biases are the direct cause of the social reality of adult higher education continues to doubt and negative outcomes.
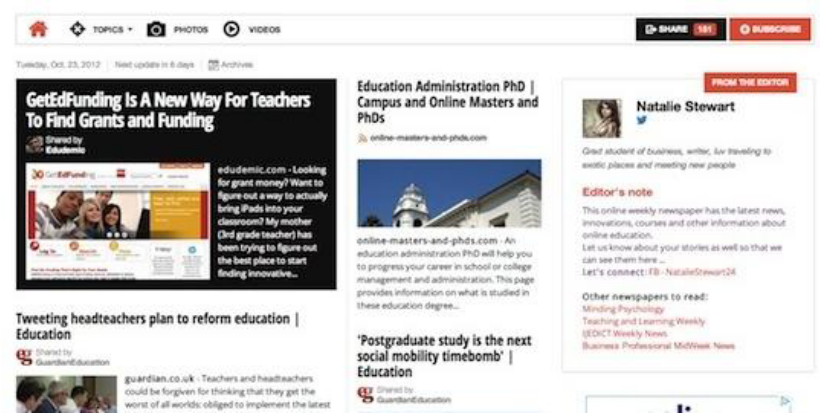

Figure 2. Online and distance learning weekly

Revenue in the heavy, light management, heavy quantity of light training under the guidance of the school tendencies, whether TV is an independent, and dependent adult education colleges (Continuing Education) School of Continuing Education in Adult Higher regarded as a way to generate income. Under the guidance of this distortion educational philosophy, the school principal continuing adult higher education setting unrealistic professional, blind expansion of enrolments, reducing teaching inputs. Teaching process of copying or imitating general higher education, "Pu enlightenment" mode, completely out of the training objectives of adult higher education to cultivate application continues skilled personnel. In addition, China Adult Higher Education shared teaching resources to continue running colleges and universities, with enrolments in colleges and universities, students in adult higher education can not continue the same teachers, experimental resources and library resources and teaching college students. Coupled with the lack of full-time teachers for adult students to understand, are not familiar with the laws of teaching adult higher education, it is difficult to achieve the desired training goal.

\section{Adult higher educations is importance of continuing education}

Traditional concepts of education will be divided into everyone's life and work of the learning period of two parts, higher education is recognized as the highest stage of life education, the adult higher education as higher education continues to supplement academic education. Adult higher education is importance of continuing education basic value orientation, resulting in higher adult continuing education with strong utilitarian overtones, ignoring the human learning process. With the social and economic changes in the structure and social changes in the population structure, increased leisure time and improvement in the level of information presented continuing education lifelong adult higher requirements, and it has the conditions for implementation. Lifelong education is not only a new concept of education, but it is also a new education system. The dominant ideology of lifelong education believes that education should relate to all aspects of life that emphasize lifelong learning educational content intrinsic link between education and the standard of living and quality of leisure education, life education is one of the higher content of continuing education for adults. Lifelong Education everyone that 
education should provide the necessary skills and knowledge in the best way, to abandon the idea of lifelong education selection of traditional education, out of action, to achieve a higher education is open to adult education recipients to meet their education the goal. Lifelong Education stressed that human life should be constantly learning and education, continue to update their knowledge structure, the idea is completely realistic needs of social development and personal growth. Lifelong Education to achieve a positive guidance for continuing adult higher education, higher sublimation adult continuing education and social development in the modernization process of the value and role of adult higher education is bound to continue to follow the traditional academic education to change the law of lifelong education.

Caption is the Adult Higher the right direction. Under the lifelong learning and learning society background, higher education will be highlighted in supply and demand, it is due to the time, energy, and economic and other reasons, can not be carried out through the normal channels, improve general higher education qualifications, and then choose the adult higher education. With the advancement of the process of popularization of higher education, enrollment ongoing work, along with the private higher education, professional and independent colleges and higher education abroad into the country, so that people can get personal qualifications to improve education through different forms of higher education. Currently, the domestic Adult Higher Education although there is some room for development, but has been unable to account for the same as before the main position, enrollment in colleges and universities to expand the number of students will inevitably affect the adult higher education continues. In addition, with the further development of the market economy, the educational needs of the public have been transformed from a single diploma to pursue the improvement of the capacity and quality. Continuing education and academic qualifications in improving education faced with dwindling situation actively carry out academic education at the same time, efforts to job training, continuing education after college, age education and leisure education and other non-academic education, continuing education is the Adult Higher the right direction.

There are two folds sound, so each one and the same at a level surface. Each sound folds itself divided down into two parts, the upper part is called the plicate, also called false vocal cords, the following section is called the lower folds, folds under what we call the usual sense of the vocal cords. False vocal cord in the normal pronunciation is not closed; it does not have a real sense of sound effects. The main role is to assist the true vocal cords false vocal cord closure.

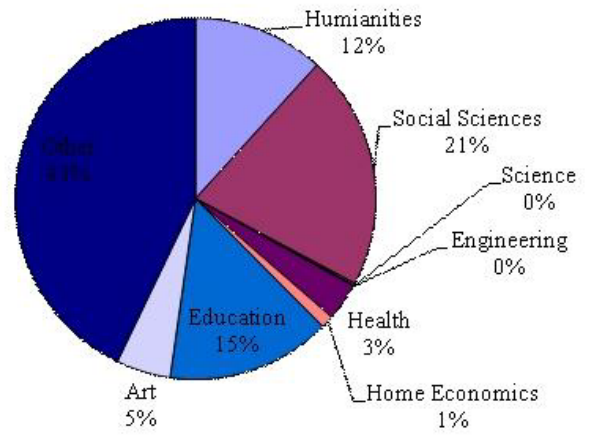

Figure 3. Distance education resource Map

Longitudinal development of adult higher education continues, countries continue to adult higher education have gone to focus on general education, vocational education and then to the core, and the development of occupational and non-occupational continuing education process. "Occupational" is inherent property of adult higher education continues, but the essential attribute of "occupation" of not continuing adult higher education. In the course of development of adult higher inertia is continuing education, occupational just important manifestation in the form of a stage. Adult Higher Education clients are mainly working, unemployed and retirees, is typical of post-secondary vocational education. Vocational education services are mainly working, unemployed adults or full-time students. In addition, adult continuing education, not only were higher employment-oriented adult vocational education, including leisure education, universities and other nonelderly "vocational" education. With the improvement of the socio-economic, cultural progress and material living standards, to meet the material needs of people on the basis of the level of spiritual life put forward a new goal. At this point, people want to accept more than is careeroriented education, but to meet the personal feelings, hobbies, leisure education and other needs of selfcultivation. Although the object of education and higher education continuing education adult content are not the same, but with adult higher education continuing education professional nature of the current and future development trends for a long period of time, but not the ultimate direction of development of adult higher education continues . With the development of society, people's living standards improve, career-oriented education will gradually move toward the edge of Adult Higher Education. At present, the overall level of development of difficult compared with developed countries, economic restructuring and industrial restructuring still need to rely on people to improve their professional competence and level to support. So, even though the ultimate goal of career-oriented adult higher education is not continuing adult higher education, but still has a special meaning of its existence in the future for a long period of time.

For a long time, much of adult higher education continue to condemn and controversy in the implementation process, in pursuit of academic qualifications for the final values reflect the utilitarian type of education, ignoring 
the needs of the people of internal development, but also affect the quality of personnel training. The careeroriented adult higher education continuing education, although a period of time to adapt to social development, but the same people did not pay attention to the needs of comprehensive development, in which case it becomes an adult higher education career development tools. In fact, in the context of a learning society, adult continuing higher education is an important way to promote universal enter a learning society, full of learning, building a learning society is the ultimate direction of development of adult higher education continues. In the future, adult higher education will continue to raise the overall quality of education goals, to conduct a full range of contact through extensive educational and social approach to actively penetrate the rural areas, communities and businesses. Therefore, changes in academic education into learning not only to build a learning society inexorable law, but also the objective requirements of adult higher education continue their own development.

Adult higher education is an effective means to manage and control the development of education. Legislation can clear the status of Adult Higher Education in Adult Higher Education in the education system, with a sense of guidance in the specification and management of adult higher education run, therefore, to promote the legislation with the help of Adult Higher Education Adult Continuing Education out of development difficulties, promote lifelong an important way of learning process. Government should pay attention to changes in general higher education, continuing to ignore the practice of adult higher education, should continue to adult higher education management as job duties related to education through increased funding, to provide policy support and other forms of adult higher education continue to guide and support, avoid adult higher education continue to continue to develop in the direction of quick success.

After merging the former Department of Adult Education explicit adult education specifically to deal with the functions, so that the development of Adult Higher Management Planning Division of Continuing Education, Basic Education, Department of Higher Education, Division of college students a clear responsibility, truly standardize management of adult education. Continue to strengthen adult higher education institutions, and encouraging private capital founded an independent adult higher education institutions continue. This adult higher education funding to ensure continuing education to some extent, dependent adult higher education colleges and universities to avoid the tendency to Cape enlightenment drawbacks. Establish a scientific and feasible, adult continuing education evaluation system of higher complex continuing adult higher education law, and by evaluating hardware and software and the quality of adult higher education institutions, such as continuing education, in the form of assessment continued to promote adult higher education institutions reform and development.

\section{Conclusion}

In the knowledge economy, higher adult continuing education course content will be constantly updated according to the social development needs, while achieving academic education function, but also to meet people's needs comprehensively improve. Modern enterprise education, community education, vocational education, knowledge and skills to improve the shortterm training updates and content-rich education, rural populations will continue our Adult Higher Education new development space. Adult Higher Education is also a concrete manifestation of lifelong continuing education in the form of continuing education after the University can undertake work to provide educational opportunities for people to have to get a college degree, and is willing to continue to receive relevant education. Therefore, adult higher education needs to continue to improve the level of training, on the basis of steady development, college education, and gradually develop job postgraduate education. In today's highly developed information technology, relying on remote technology actively, improve remote mode adult higher education continues to regional economic and social development in rural areas requires knowledge of the economic development of agriculture, rural and remote areas to train practical talents.

\section{References}

1. Should Wangjiang China Education Reform and Development for 30 years. Shanghai: Shanghai University of Finance and Economics Press, 105(2008)

2. Maoyuan China popularization of higher education structures and systems. Guangzhou: Guangdong Higher Education Press, 14(2009)

3. Du to Germany, Yaoyuan Feng, Li Xing-Dong Toward Development of Adult Education. Beijing: China Renmin University Press, 267(2007)

4. He Qizong new era of education - theory and practice of lifelong education. Beijing: People's Publishing House, 23(2008)

5. Zhao new study occupational characteristics of the Adult Higher Education - Xiamen five universities, for example the status of implementation of Adult Higher Education. Xiamen University, master's thesis, 251(2007)

6. High Zhimin, Cai Baotian social transition adult education, lifelong education and research. Beijing: Capital Normal University Press, 112(2007) 